The Version of Record of this manuscript has been published and is available in Music Education Research (August 12 ${ }^{\text {th }}, 2020$ ).

https://www.tandfonline.com/doi/abs/10.1080/14613808.2020.1806809

\title{
Isolation at the workplace: The case of music teachers in the Spanish primary education system
}

\author{
Rolando Angel-Alvarado ${ }^{\mathrm{a} *}$, Olga Belletich ${ }^{\mathrm{b}}$ and Miguel R. Wilhelmi ${ }^{\mathrm{b}}$ \\ ${ }^{a}$ Music Institute, Alberto Hurtado University, Santiago, Chile; ${ }^{b}$ Faculty of Human and \\ Social Sciences, Public University of Navarre, Pamplona, Spain
}

*Corresponding author: Music Institute, Alberto Hurtado University, 31 Almirante

Barroso Street, ZIP 8340540 Santiago, Chile. E-mail address:

rolando.angel.alvarado@gmail.com

\section{Declaration of interest statement}

The data that support the findings of this study are openly available in Academica-e at https://academica-e.unavarra.es/xmlui/handle/2454/32531.

\begin{abstract}
This study aims to establish whether music teachers feel isolated at the workplace or not because only one music teacher is part of teaching staff in a primary school by reasons linked to the limited school budget. A nonexperimental quantitative research design was utilised in this study because two psychological scales have been applied, considering a random cluster sample, which is understood as a probability sampling because the number of participants has representativeness in a national level. Results demonstrate that music teachers work alone at schools, such that they have limited chances for interacting with other music educators at the workplace. In conclusion, job isolation is the turning point for understanding the motivational status of music teachers. Given these findings, some practical implications are proposed herein.
\end{abstract}

Keywords: self-determination theory; basic psychological needs; music teaching; loneliness: solitude. 


\section{Isolation at the workplace: The case of music teachers in the Spanish primary education system}

\section{Introduction}

The goal of this study is to establish whether music teachers feel isolated at the workplace or not, as the group mentioned above understands isolation as "a difficult and sometimes painful working condition; it reflects the individual nature of the teachers' experience, particularly as juxtaposed in a school culture full of people; it also serves as an adaptive strategy" (Sindberg 2014, 398). The individual nature is observed in primary schools because, in general terms, only one music teacher is part of teaching staff in a primary school by reasons linked to time reduction for music teaching and limited school budget for employing a specialist music teacher (de Vries 2018; Sindberg 2011). In this scenario, music teachers deal with professional isolation, making it plausible that some educators accept the solitude emotionally at the workplace, while others feel isolated by peers (Nguyen, Ryan, and Deci 2018; Shaw 2018). In both cases, music teachers have scarce chances for interacting pedagogically with other music educators, and the most worrisome, they may undervalue the importance of interacting with peers who teach other subjects (Carrillo 2015).

To carry out this study, two psychological scales have applied to a national sample from Spain, which is integrated by music teachers and primary school educators who impart other subjects. Both scales provide ordinal data, such that information is analysed through percentual distribution and nonparametric tests (Hinton 2014), in addition to Pearson correlation (Stangor 2011). In view of these methodological decisions, this quantitative study will delve into job isolation of music teachers from a hermeneutic circle (Angel-Alvarado and Alamos 2018), attempting to intertwine 
consistently practical results with the existent theoretical knowledge provided by SelfDetermination Theory (SDT).

\section{Delving into SDT: Autonomous motivation and three basic psychological needs}

According to SDT, autonomous motivation implies high levels of intrinsic motivation as well as identified regulation (Riley 2016), which in practical terms mean that teachers enjoy carrying out activities and they are aware that teaching actions have an impact on the mental health of students (Deci and Ryan 2000). These conceptualisations display that environmental factors affect positively or negatively in autonomous motivation (Martínez, Berthel, and Vergara 2017; Ryan and Deci 2000; Vansteenkiste and Ryan 2013), such that basic psychological needs for autonomy, competence, and relatedness take relevance (Gagné 2009). The satisfaction of these three basic psychological needs in high levels of autonomous motivation may entail the internalisation of self-determined behaviours, understanding self-determination as the capacity to regulate behaviour based on the pleasure that the activity gives to an individual (Ryan and Deci 2017).

SDT postulates three basic psychological needs in order to delve into the relationships between environmental factors and the individual's mental health (Ryan and Deci 2019). That is, basic psychological needs promote or discourage autonomous motivation. The first need is autonomy, which involves the desire for choice and feeling of willpower during a specific task (Uysal, Lee, and Knee 2010). Secondly, the need for competence is understood as the desire for optimal interaction within the workplace in order to achieve desired results (Baard, Deci, and Ryan 2004). Finally, the third basic psychological need is relatedness, which involves being attuned to the social 
environment through attention and interpersonal knowledge (Van den Broeck et al. 2010).

It should be emphasised that the three basic psychological needs have the same importance because they are interrelated (González-Cutre et al. 2016). However, SDT claims that the need for autonomy is essential because it promotes self-determined behaviour and is negatively related to the subjugation facing authoritarian leadership (Van den Broeck et al. 2010; Angel-Alvarado, Wilhelmi, and Belletich 2020). In contrast, the needs for competence and relatedness can also be satisfied in contexts where subjugated behaviour is promoted (Deci and Ryan 2000). In any case, it does not mean that autonomous teacher will necessarily promote the autonomy in students because music teachers enjoy conducting activities in the classroom even when their educational practices are based on authoritarian teaching methods (Gabnyté and Strakšiené 2014; Torres 2017).

It is important to indicate that the three basic psychological needs have been analysed deeply from the perspective of student learning in musical situations (e.g. Bonneville-Roussy et al. 2017; Evans 2015; Evans and Liu 2019; Evans, McPherson, and Davidson 2012; Kingsford-Smith and Evans 2019). Nonetheless, basic psychological needs are a pending matter in music teacher motivation because there is only a couple of studies reporting evidence about the phenomenon.

Firstly, Angel-Alvarado and Alamos (2018) have reported that teacher motivation can trigger a change of plans in the life project of an educator, as they narrate the story of a music teacher who had intentions of conducting a guitar ensemble by two years, but he is still carrying out the activity ad honorem since 2001 . Another example is reported by Angel-Alvarado, Belletich, and Wilhelmi (in press), who have informed that the music teachers' autonomous motivation in classroom settings is 
hampered by different factors of the education system, such as curriculum, teacher beliefs, student behaviours, and school community. In this last factor, the report emphasises that education system gives rise to job isolation in music teachers because they work alone at schools. That is, the distribution of the few jobs in the schools, for the occupation of a music teacher, does not allow the creation of a teaching team from the same professional area.

\section{Method}

This research project has taken Design-Based Research because mixed research methods are essential for investigating education phenomena (Angel-Alvarado, Wilhelmi, and Belletich 2019). It is useful for both researchers and educators because it provides theoretical and practical knowledge within teaching and learning situations, given that educational activities are theoretically grounded, empirically contrasted, and they could be repeatable. In view of this holistic approach, it is convenient to inform that only matters referred to nonexperimental quantitative research design are reported herein.

\section{Context}

In the particular case from Spain, music education was considered as a compulsory subject in primary education until the implementation of the Organic Law for the Improvement of Education Quality in 2015. This education policy triggered a detriment of the subject, becoming it an elective subject in the national curriculum for primary education (Belletich, Wilhelmi, and Angel-Alvarado 2016). In fact, the new education policy has brought, as a consequence, that music teachers work alone because schools require contracting only one educator for imparting the subject in different primary educational levels. However, the most worrisome is that some music teachers are 
teaching other subjects in order to comply with working timetables, transforming music teaching in an emotional escape mechanism (Angel-Alvarado, Belletich, and Wilhelmi in press).

\section{Participants}

In Spain, six autonomous communities - Aragon, Balearic Islands, Basque Country, Castile and Leon, Chartered Community of Navarre, and Community of Madrid - have published full primary school lists through their official websites where they provide relevant institutional information such as a postal address, telephone number, e-mail, and so on. In this study, all educators belonging to those educational contexts were invited with the intention of ensuring those teachers had the same participation chances. That is, random cluster sampling is done because a sampling unit encompasses an individual's group. The sample is understood then as probability sampling, so different statistical techniques can be utilised for establishing the sample size.

According to the updated official statistics from Spain, the sample size has statistical representativeness because more than 655 teachers, who work in primary education, participated in this study. The sample size was calculated based on three quantitative conditions (Hair et al. 2015): a confidence level of $99 \%(\alpha=.01)$, a margin of error of $5 \%$, and a proportion equivalent to $50 \%$. The total sample has been divided into two clusters. The first conglomerate is made up of educators who do not teach music in primary schools $(\mathrm{n}=660)$, while the second group incorporates all music teachers $(n=70)$. The second cluster's proportion is approximately $10 \%$ of the total educator sample. Therefore, both groups overcome five times the full quantity of applied items (Lévy and Varela 2006) on each scale. 


\section{Statistical hypothesis}

The thorough internalisation of intrinsic motivation and identified regulation have a positive impact on autonomous motivation, according to the self-determination continuum (Gagné and Deci 2005; Howard, Gagné, and Bureau 2017). Nevertheless, self-determined behaviour depends on the satisfaction of the three basic psychological needs. This means that all self-determined behaviours imply autonomous motivations, but not all autonomous motivations involve self-determined behaviours. They are not synonymous.

SDT establishes the hypothesis that self-determined behaviours depend on the satisfaction of the three basic psychological needs (Gagné 2009), which means that intrinsic motivation and identified regulation are internalised only in environments where all basic psychological needs are supported. In this study, the SDT's hypothesis is given with the intention of statistically testing it in a national sample.

The Pearson correlation coefficient for significance is used for testing the hypothesis, so the null hypothesis implies no significant correlation and the alternative hypothesis states that a significant correlation exists (Schumacker and Tomek 2013; Wilcox 2013). The significance level is $1 \%(\alpha=.01)$, and the alternative hypothesis aims in a positive direction. The statistical hypotheses are stated next:

- Null hypothesis: Self-determined teachers do not show significant positive correlations between autonomous motivation and the three basic psychological needs in classroom situations.

- Alternative hypothesis: Self-determined teachers show significant positive correlations between autonomous motivation and the three basic psychological needs in classroom situations. 


\section{Measures}

Teacher motivation. The Work Tasks Motivation Scale for Teachers (WTMST; Fernet et al. 2008) was applied in this study, using a Spanish translation of the framework of autonomous motivation (Ruiz 2015). Therefore, the measure consists of six items that are distributed in two subscales: intrinsic motivation (three items; e.g., because I like doing this task) and identified regulation (three items; e.g., because it is important for me to carry out this task). These six items are rated on a seven-point Likert-type scale ranging from 1 (does not correspond at all) to 7 (absolutely correspond). In the current study, the WTMST Spanish version indicated a Cronbach Alpha coefficient of .796, which is acceptable because it is greater than .70 . The observed goodness-of-fit indices were also acceptable $(\mathrm{NFI} \geq .95 ; \mathrm{TLI} \geq .95 ; \mathrm{CFI} \geq .95$, and $\mathrm{RMSEA} \leq .08)$.

Teacher's basic psychological needs. The original version of the Basic Psychological Needs Scale for Teachers (BPNS-T; Angel-Alvarado, Wilhelmi, and Belletich in press) was applied in this study (English translation in Appendix I). The measure consists of seven items that are distributed in three subscales: need for autonomy (two items; e.g., I can make decisions about my syllabus), need for competence (three items; e.g., students say that I am a good teacher), and need for relatedness (two items, e.g., I like people I work with). These seven items are rated on a five-point Likert-type scale ranging from 1 (does not correspond at all) to 5 (absolutely correspond). In the current study, the BPNS-T indicated a Cronbach Alpha coefficient of .78, which is acceptable because it is greater than .70 . The goodness-of-fit indices were also acceptable (NFI $\geq .95 ;$ TLI $\geq$ $.95 ; \mathrm{CFI} \geq .95$, and RMSEA $\leq .08)$. 


\section{Data collection procedures}

A formal invitation was submitted to the school e-mails belonging to the six autonomous communities due to the Spanish data protection regulation. Researchers requested school administrations share the access link, which was attached to the email, with the teaching staff. Through Google Forms, educators read the conditions of participation, instructions, and the confidentiality agreement as part of the ethical protocol established for conducting the research activity. Therefore, in conformity with the European ethical research rules (European Union 2013), all participant teachers freely applied both the Spanish version of the WTMST and BPNS-T, as well as gave some contact information by their own accord. Data collection had a duration of one month, such that researchers closed the online access after 30 days. The feedback received from participants was favourable as they positively appraised the research matter.

\section{Data analysis procedures}

Using SPSS, both groups of teachers are contrasted regarding motivational categories and basic psychological needs. Firstly, both clusters are analysed through the Kolmogorov-Smirnov test with the intention of establishing whether each sample shows a normal distribution or not. Subsequently, those clusters are compared through Levene's Test and one-way ANOVA because the former procedure allows verifying whether the variance is homogeneous or not between both sampling units, while the one-way ANOVA is useful for observing whether there is mean equality or not. All these tests consider the established significance level $(\alpha=.01)$ for determining if differences in alternative hypotheses are accepted or rejected. 
Subsequently, it is appropriate to utilise nonparametric alternatives for establishing statistical differences between both clusters (McMillan and Schumacher 2012; Rosenthal 2012) because the two scales provide ordinal data, which are expressed using percentages (Hinton 2014). Specifically, the Mann-Whitney U test is used for establishing statistical differences in motivational categories as well as basic psychological needs, considering the established significance level $(\alpha=.01)$.

Finally, the Pearson correlation coefficient ( $\mathrm{r}$ of Pearson) specifies the direction and magnitude of the linear association between two numerical variables. The direction's range can fluctuate between -1.00 to +1.00 . Therefore, positive values indicate a positive linear relationship between variables, while negative values imply a negative or inverse linear relationship. The effect size is depicted by the absolute value of the Pearson correlation coefficient (Stangor 2011). It is imperative to indicate that the statistical hypothesis is tested during this procedure, focusing on $\rho$-values, considering the established significance level.

\section{Results}

\section{Motivational categories}

In the comparison between groups of teachers who teach music at school and those who do not, the following outcomes materialised (Table 1). On the Kolmogorov-Smirnov test's organised output by groups, the non-music teachers' cluster rejected the normal distribution $(\rho<.01)$ in both motivational categories. However, the music teachers' conglomerate accepted a normal distribution in intrinsic motivation $(\rho=.068)$ and identified regulation $(\rho=.159)$ as their $\rho$-values were higher than the significance level. Subsequently, both groups were compared through the Levene's test and one-way 
ANOVA, showing homogeneity of variance as well as mean equality in both motivational categories as $\rho$-values were greater than the significance level.

The Mann-Whitney U test indicated statistically nonsignificant differences between both conglomerates in intrinsic motivation $(\rho=.11)$ and identified regulation $(\rho=.27)$ because their $\rho$-values are higher than the significance level. Therefore, statistically nonsignificant differences are observed in motivational categories between teachers' groups. That is, statistically nonsignificant differences were seen in autonomous motivation between educators who teach music in schools and teachers who do not.

\section{Basic psychological needs}

In the comparison between groups of teachers, the following outcomes materialised (Table 2). On the Kolmogorov-Smirnov test's organised output by groups, the nonmusic teachers' cluster rejected the normal distribution $(\rho<.01)$ in the three basic psychological needs. However, the music teachers' group accepted a normal distribution only in the need for competence $(\rho=.042)$ because its $\rho$-value was higher than the significance level. Subsequently, both groups were compared through the Levene's test and one-way ANOVA. All basic psychological needs show homogeneity of variance as well as mean equality due to $\rho$-values were greater than the significance level.

Regarding Mann-Whitney U test, results indicated statistically nonsignificant differences between both groups in needs for autonomy $(\rho=.47)$, competence $(\rho=.57)$, and relatedness $(\rho=.04)$ because their $\rho$-values are higher than the significance level. Therefore, statistical outcomes demonstrate that the three basic psychological needs show statistically nonsignificant differences between music teachers and educators who 
do not teach music at school. However, it is important to consider that the obtained result in the need for relatedness could be considered as a significant difference in a scale that is less demanding.

\section{Correlations between motivational categories and basic psychological needs}

In Table 3, the non-music teachers' sample indicates significant positive correlations between motivational categories and each basic psychological need. Regarding music teachers, intrinsic motivation shows a significant weak positive correlation with needs for autonomy and relatedness, while the correlation is significant moderate positive with the need for competence. The identified regulation shows a significant weak positive correlation with the need for autonomy, but the correlation with the need for competence is significant and moderately positive. It is important to highlight that the correlation between identified regulation and need for relatedness is rejected because its $\rho$-value is higher than the significance level $(\alpha=.01)$, which means that the estimated coefficient is equal to zero. Therefore, identified regulation and the need for relatedness are statistically independent. In other words, music teachers have difficulties interacting with their peers in pedagogical terms.

In view of these results, SDT's hypothesis is proven statistically because intrinsic motivation and identified regulation show significant positive correlations with the three basic psychological needs in the non-music teachers' sample, but the cluster integrated by music teachers does not prove the SDT's hypothesis. Therefore, the alternative hypothesis is accepted - considering an error measurement of $1 \%(\rho<.01)-$ because self-determined teachers show significant positive correlations between autonomous motivation and the three basic psychological needs in classroom situations. The acceptance of the alternative hypothesis implies that self-determination is not 
achieved by music teachers because, to some extent, autonomous motivation and need for relatedness are statistically independent.

\section{Discussion}

Nonsignificant differences are observed between both teacher groups in motivational categories and satisfaction of the three basic psychological needs. However, it is appropriate to evaluate the need for relatedness frequently because its value could be considered as a significant difference in a scale that is less demanding. This finding makes it probable that music teachers have difficulties in interacting with peers because the importance of professional attunement is undervalued by them (Carrillo 2015). In other words, music teachers feel pleasure in undertaking teaching tasks because they can act autonomously in the classroom (Juntunen 2017), but they have likely problems in undertaking interdisciplinary projects in the educational context (Davidson and Dwyer 2014; Sindberg 2014).

Considering this finding, it is convenient to recall that intrinsic motivation and identified regulation are considered within the framework of autonomous motivation (Gagné and Deci 2005). Therefore, greater autonomous motivation increases the chances of self-determination. However, self-determination depends on the satisfaction of the three basic psychological needs obligatorily (Gagné 2009). Thus, the acceptance of the alternative hypothesis has implications in the sample of music teachers because identified regulation is not significantly correlated with the need for relatedness. It immediately indicates that music teachers perceive autonomous motivation, but they are not experiencing self-determination because it may be internalised only in environments where the three basic psychological needs are supported (Deci and Ryan 2000).

Given this finding linked to relatedness, it is appropriate to asseverate that the 
job isolation is negatively affecting autonomous motivation of music teachers because, even when they enjoy carrying out activities and are aware that teaching actions have an impact on mental health of students, they have difficulties in regulating their behaviours based on the pleasure that the teaching task gives them. Those difficulties make mainly reference to social relationships with peers (Ballantyne and Zhukov 2017; Carrillo, Baguley, and Vilar 2015; Erss, Kalmus, and Autio 2016; Hanson 2017), affecting even in own desired personal and professional goals (Johnson and Matthews 2017; Shaw 2018; Spruce and Bol 2015). Therefore, the loneliness would influence on teacher autonomy (Sindberg 2014), to the point that it is reasonable to establish that the teacher autonomy is satisfied through the job isolation because music education is considered an elective subject in the Spanish curriculum for primary education (Belletich, Wilhelmi, and Angel-Alvarado 2016). In this scenario, schools do not require contracting more than one specialist music teacher (Angel-Alvarado, Belletich, and Wilhelmi in press; de Vries 2018; Sindberg 2011).

\section{Conclusions}

Self-determination is perceived only by teachers who do not impart music education at schools because the three basic psychological needs are correlated with autonomous motivation. In the case of music teachers, self-determination is not achieved as autonomous motivation is correlated only with needs for autonomy and competence, which implies that the need for relatedness and autonomous motivation are statistically independent. That is, both variables indicate a degree of correlation equal to zero. It is important to recall that the need for relatedness involves an attunement with the milieu, such that findings reveal that music teachers are experiencing job isolation.

Two reasons trigger the loneliness at work. Firstly, music teachers undervalue 
the importance of interacting with peers who impart other subjects because, in pedagogical terms, procedures of instruction and assessment are different among subjects. This situation would reduce the chances of undertaking interdisciplinary educational projects. Secondly, music teachers work alone at schools, such that they have limited chances for interacting with other music educators at the workplace.

In view of job isolation, it is appropriate to declare that the autonomy of music teachers implies a loneliness de facto. Indeed, music teachers would have a desire for choice and feeling of willpower during an activity, but such teacher autonomy is satisfied only because they work alone at primary school. Therefore, teacher autonomy is satisfied in an unsuitable way by the education system, given that the statistical independence of teacher relatedness is observed as a determinant factor for supporting the need for autonomy. In conclusion, job isolation is the turning point for understanding autonomous motivation of music teachers as, even when they perceive high degrees of autonomy and competence in teaching tasks, the isolation at workplace affects in their daily routines to the point that they are forced to deal with pedagogical problems alone, given that no specialist peer works at school.

Two practical implications arise from this finding. Firstly, it is imperative that school administrations invest in continuous training for all teachers in areas linked to music teaching, given that it would not have only an impact on relationships at work between teachers, but also has implications on the confidence between members of the school and social community. Secondly, it is necessary to strengthen professional fellowship between music teachers and their peers from other curricular areas, through the realisation of interdisciplinary and collaborative educational projects. All these activities would affect directly on the educational culture of schools, entailing the improvement of environmental factors and, therefore, teachers' beliefs. In view of these 
implications, it is important to consider the job isolation as a notorious problem that should be studied internationally. Therefore, it is imperative to replicate this study in other national education systems in order to establish whether the job isolation is a worldwide trend or not, as well as to determine a set of good practices for improving working conditions of music teachers.

\section{Acknowledgements}

The first author acknowledges CONICYT PFCHA/DOCTORADO BECAS CHILE/2015 for his doctoral scholarship. This study also received funding from the State I+D+i Programme Oriented Toward Challenges of the Society, under grant number EDU2017-84979-R.

\section{Declaration of interest statement}

Authors report no potential conflict of interest.

\section{References}

Angel-Alvarado, Rolando, and José Alamos. 2018. "Musical Conducting in the Guitárregas Guitar Ensemble: A Leadership Based on the Self-determination of Music Teachers." Revista Internacional de Educación Musical 6 (1): 53-61. doi: $10.1177 / 230748411800600105$

Angel-Alvarado, Rolando, Miguel R. Wilhelmi, and Olga Belletich. 2019. "Holistic Architecture for Music Education: A Research Design for Carrying Out Empiric and Interdisciplinary Studies in Didactics of Music.” Itamar (5): 335-357.

Angel-Alvarado, Rolando, Miguel R. Wilhelmi, and Olga Belletich. in press. "Construct Validity: Basic Psychological Needs Scale for Teachers.” Journal for Educators, Teachers and Trainers.

Angel-Alvarado, Rolando, Miguel R. Wilhelmi, and Olga Belletich. 2020. "Teaching Autonomy: Does Spanish Education System Achieve the Desired Effect?" Psychology, Society, \& Education. doi:10.25115/psye.v0i0.2585 
Angel-Alvarado, Rolando, Olga Belletich, and Miguel R. Wilhelmi. in press. "Exploring Motivation in Music Teachers: The Case of Three Primary Schools.” British Journal of Music Education.

Baard, Paul P., Edward L. Deci, and Richard M. Ryan. 2004.” Intrinsic Need Satisfaction: A Motivational Basis of Performance and Well-Being in Two Work Settings." Journal of Applied Social Psychology 34: 2045-2068. doi:10.1111/j.15591816.2004.tb02690.x

Ballantyne, Julie, and Katie Zhukov. 2017. "A Good News Story: Early-Career Music Teachers' Accounts of their "Flourishing" Professional Identities." Teaching and Teacher Education 68: 241-251. doi:10.1016/j.tate.2017.08.009

Belletich, Olga, Miguel R. Wilhelmi, and Rolando Angel-Alvarado. 2016. "La educación musical en la formación básica en España: El problema de la dispersión curricular." Perspectiva Educacional 55 (2): 158-170. doi:10.4151/07189729Vol.55-Iss.2-Art.454

Bonneville-Roussy, Arielle, Paul Evans, Jérémie Verner-Filion, Robert J. Vallerand, and Thérèse Bouffard. 2017. "Motivation and Coping with the Stress of Assessment: Gender Differences in Outcomes for University Students." Contemporary Educational Psychology 48: 28-42. doi:10.1016/j.cedpsych.2016.08.003

Carrillo, Carmen. 2015. "Music Teachers Professional Competences: From a Theoretical Framework to a Concrete Proposal.” Revista Internacional de Educación Musical (3): 11-21. doi:10.12967/RIEM-2015-3-p011-021

Carrillo, Carmen, Margaret Baguley, and Mercè Vilar. 2015. "The Influence of Professional Identity on Teaching Practice: Experiences of Four Music Educators." International Journal of Music Education 33 (4): 451-462. doi:10.1177/0255761415582348

Davidson, Jayne, and Rachael Dwyer. 2014. "The Role of Professional Learning in Reducing Isolation Experienced by Classroom Music Teachers." Australian Journal of Music Education (1): 38-51.

Deci, Edward L., and Richard M. Ryan. 2000. "The "What" and "Why" of Goal Pursuits: Human Needs and the Self-Determination of Behavior." Psychological Inquiry 11 (4): 227-268. 
de Vries, Peter A. 2018. “Teaching Primary School Music: Coping with Changing Work Conditions." Music Education Research $20 \quad$ (2): 201-212. doi:10.1080/14613808.2016.1269734

Erss, Maria, Veronika Kalmus, and Tero H. Autio. 2016. "Walking a Fine Line': Teachers' Perception of Curricular Autonomy in Estonia, Finland and Germany”.” Journal of Curriculum Studies $48 \quad$ (5): 589-609. doi:10.1080/00220272.2016.1167960

European Union. 2013. Ethics for Researchers: Facilitating Research Excellence in FP7. 1st ed Luxembourg: Publication Office of the EU.

Evans, Paul. 2015. "Self-Determination Theory: An Approach to Motivation in Music Education." Musicae Scientiae 19 (1): 65-83. doi:10.1177/1029864914568044

Evans, Paul, and Mark Y. Liu. 2019. "Psychological Needs and Motivational Outcomes in a High School Orchestra Program." Journal of Research in Music Education 67 (1): 83-105. doi:10.1177/0022429418812769

Evans, Paul, Gary E. McPherson, and Jane W. Davidson. 2012. "The Role of Psychological Needs in Ceasing Music and Music Learning Activities." Psychology of Music 41 (5): 600-619. doi:10.1177/0305735612441736

Fernet, Claude, Caroline Senécal, Frédéric Guay, Herbert Marsh, and Martin Dowson. 2008. "The Work Tasks Motivation Scale for Teachers (WTMST)." Journal of Career Assessment 16 (2): 256-279. doi:10.1177/1069072707305764

Gabnyté, Giedré, and Diana Strakšiené. 2014. "Occupational Motivation of Music Teachers as Significant Factor of Social Wellbeing." Social Welfare: Interdisciplinary Approach 4 (1): 64-70.

Gagné, Marylène, and Edward L. Deci. 2005. "Self-Determination Theory and Work Motivation.” Journal of Organizational Behavior 26 (4): 331-362.

Gagné, Marylène. 2009. “A Model of Knowledge-Sharing Motivation.” Human Resource Management 48 (4): 571-589.

González-Cutre, David, Álvaro Sicilia, Ana C. Sierra, Roberto Ferriz, and Martin S. Hagger. 2016. "Understanding the Need for Novelty from the Perspective of SelfDetermination Theory." Personality and Individual Differences 102: 159-169. doi:10.1016/j.paid.2016.06.036 
Hair, Joseph F., Mary Wolfinbarger, Arthur H. Money, Phillip Samouel, and Michael J. Page. 2015. Essentials of Business Research Methods. 2nd ed. New York: Routledge.

Hanson, Josef. 2017. "Exploring Relationships between K-12 Music Educators' Demographics, Perceptions of Intrapreneuring, and Motivation at Work." Journal of Research in Music Education 65 (3): 309-327. doi:10.1177/0022429417722985

Hinton, Perry. R. 2014. Statistics Explained. 3rd ed. New York: Routledge.

Howard, Joshua L., Marylène Gagné, and Julien S. Bureau. 2017. "Testing a Continuum Structure of Self-Determined Motivation: A Meta-Analysis." Psychological Bulletin 143 (12): 1346-1377. doi:10.1037/bul0000125

Johnson, Daniel C., and Wendy K. Matthews. 2017. "Experienced General Music Teachers' Instructional Decision Making." International Journal of Music Education 35 (2): 189-201. doi:10.1177/0255761415620531

Juntunen, Marja-Leena. 2017. "National Assessment Meets Teacher Autonomy, National Assessment of Learning Outcomes in Music in Finnish Basic Education." Music Education Research 19 (1): 1-16. doi:10.1080/14613808.2015.1077799

Kingsford-Smith, Andrew, and Paul Evans. 2019. "A Longitudinal Study of Psychological Needs Satisfaction, Value, Achievement, and Elective Music Intentions." Psychology of Music: 1-17. doi:10.1177/0305735619868285

Lévy, Jean-Pierre, and Jesús Varela, J. 2006. Modelización con estructuras de covarianza en Ciencias Sociales: Temas esenciales, avanzados y aportaciones especiales. La Coruña: Netbiblo.

Martínez, Judith C., Yamileth Berthel, and Mary S. Vergara. 2017. "Burnout Syndrome in Teachers and its Relation with the Learning of Primary Students of an Official Educational Institution of Sincelejo (Colombia), 2016.” Salud Uninorte, 33 (2): 118-128.

McMillan, James H., and Sally Schumacher. 2012. Investigación educativa. 5th ed. Madrid: Pearson Educación. 
Nguyen, Thuy-vy T., Richard M. Ryan, and Edward L. Deci. 2018. "Solitude as an Approach to Affective Self-Regulation." Personality and Social Psychology Bulletin 44 (1): 92-106. doi:10.1177/0146167217733073

Riley, Gina. 2016. "The Role of Self-Determination Theory and Cognitive Evaluation Theory in Home Education." Cogent Education 3 (1): 1-7. doi:10.1080/2331186X.2016.1163651

Rosenthal, James. A. (2012). Statistic and Data Interpretation for Social Work. 1st ed. New York: Springer.

Ruíz, María. 2015. "Soporte de autonomía y motivación en educación: Consecuencias a nivel global y contextual.” PhD diss., Universitas Miguel Hernández.

Ryan, Richard M., and Edward L. Deci. 2000. "The Darker and Brighter Sides of Human Existence: Basic Psychological Needs as a Unifying Concept.” Psychological Inquiry 11 (4), 319-338. doi:10.1207/S15327965PLI1104_03

Ryan, Richard. M., and Edward L. Deci. 2017. Self-Determination Theory: Basic Psychological Needs in Motivation, Development, and Wellness. New York: The Guilford Press.

Ryan, Richard M., and Edward L. Deci. 2019. "Brick by Brick: The Origins, Development, and Future of Self-Determination Theory." Advances in Motivation Science 6: 111-162. doi:10.1016/bs.adms.2019.01.001

Schumacker, Randal, and Sara Tomek. 2013. Understanding Statistics using R. New York: Springer.

Shaw, Julia T. 2018. "Pedagogical Context Knowledge: Revelations from a Week in the Life of Itinerant Urban Music Educators.” Music Education Research 20 (2): 184200. doi:10.1080/14613808.2016.1238062

Sindberg, Laura. 2011. "Alone All Together - The Conundrum of Music Teacher Isolation and Connectedness." Bulletin of the Council for Research in Music Education (189): 7-22. doi:10.5406/bulcouresmusedu.189.0007

Sindberg, Laura. K. 2014. "Perceptions and Perspectives of Music Teachers in Urban Settings: Isolation, Conversation and Collaboration." Music Education Research 16 (4): 387-403. doi:10.1080/14613808.2013.848849 
Spruce, Robin, and Linda Bol. 2015. "Teacher Beliefs, Knowledge, and Practice of SelfRegulated Learning." Metacognition and Learning 10 (2): 245-277. doi:10.1007/s11409-014-9124-0

Stangor, Charles. 2011. Research Methods for the Behavioral Sciences. 4th ed. Belmont: Wadsworth.

Torres, Gabriela. 2017. 'Intrinsic Motivation and Flow Condition on the Music Teacher's Performance." Research in Pedagogy 7 (1): 145-157. doi:10.17810/2015.56

Uysal, Ahmet, Helen Lee, and C. Raymond Knee. 2010. "The Role of Need Satisfaction in Self-Concealment and Well-Being." Personality and Social Psychology Bulletin 36 (2): 187-199.

Van den Broeck, Anja, Maarten Vansteenkiste, Hans De Witte, Bart Soenens, and Willy Lens. 2010. "Capturing Autonomy, Competence, and Relatedness at Work: Construction and Initial Validation of the Work-Related Basic Need Satisfaction Scale.” Journal of Occupational and Organizational Psychology 83: 981-1002. doi:10.1348/096317909X481382

Vansteenkiste, Maarten, and Richard M. Ryan. 2013. "On Psychological Growth and Vulnerability: Basic Psychological Need Satisfaction and Need Frustration as a Unifying Principle." Journal of Psychotherapy Integration 23 (3): 263-280. doi:10.1037/a0032359

Wilcox, Rand. 2013. Introduction to Robust Estimation and Hypothesis Testing. 3rd ed. Waltham: Elsevier. doi:10.1016/C2010-0-67044-1 


\section{Appendix I. English version of the BPNS-T}

\section{Autonomy}

I feel at liberty to teach in the way I consider most appropriate.

I can make decisions about my syllabus.

\section{Competence}

Students say that I am a good teacher.

I get on well with my students.

My students value and appreciate me.

\section{Relatedness}

When I share with people in my working environment, I trust them.

I like people I work with. 


\section{Tables}

Table 1. Descriptive statistics of motivational categories, according to the output by teacher groups.

\begin{tabular}{lccc}
\hline & & Distribution (\%) \\
& High level & Middle level & Low level \\
\hline Non-music teachers (n=660) & 55 & 30 & 15 \\
Intrinsic Motivation & 45 & 33 & 22 \\
Identified Regulation & & & \\
\hline Music teachers (n=70) & 49 & 35 & 16 \\
Intrinsic Motivation & 40 & 31 & 29 \\
Identified Regulation & & & \\
\hline
\end{tabular}

Data collected through the WTMST' Spanish version.

Source: Own elaboration.

Table 2. Descriptive statistics of the satisfaction of basic psychological needs, according to the output by teacher groups.

\begin{tabular}{lccc}
\hline & High level & $\begin{array}{c}\text { Distribution (\%) } \\
\text { Middle level }\end{array}$ & Low level \\
\hline Non-music teachers (n=660) & & & \\
Autonomy & 69 & 26 & 5 \\
Competence & 62 & 35 & 3 \\
Relatedness & 78 & 18 & 4 \\
\hline Music teachers (n=70) & 77 & 19 & 4 \\
Autonomy & 63 & 31 & 6 \\
Competence & 73 & 26 & 1 \\
Relatedness & & & \\
\hline
\end{tabular}

Data collected through BPNS-T.

Source: Own elaboration.

Table 3. Coefficients of determination ( $r$ of Pearson) between motivational categories and basic psychological needs.

\begin{tabular}{lccc}
\hline Basic psychological needs & Autonomy & $\begin{array}{c}\text { r of Pearson } \\
\text { Competence }\end{array}$ & Relatedness \\
\hline $\begin{array}{l}\text { Non-music teachers }(\mathrm{n}=660) \text { : Motivational } \\
\text { categories }\end{array}$ & & & $.26^{*}$ \\
Intrinsic Motivation & $.38^{*}$ & $.46^{*}$ & $.45^{*}$ \\
\hline $\begin{array}{l}\text { Identified Regulation } \\
\text { Music teachers (n=70): Motivational }\end{array}$ & $.36^{*}$ & & $.36^{*}$ \\
categories & & $.57^{*}$ & .15 \\
Intrinsic Motivation & $.34^{*}$ & $.51^{*}$ & \\
Identified Regulation & & & \\
\hline
\end{tabular}

$* \mathrm{p}<.01$

Data collected through the WTMST' Spanish version and BPNS-T.

Source: Own elaboration. 